\title{
Bid to protect wolves from genetic pollution
}

Paris. A group of European animal rights and conservation organizations announced last week that it is setting up a European 'Wolf Federation' to seek better legal protection for the wolf, an endangered species in most parts of Europe - both physically and by 'genome pollution' through contact with both feral and domestic dogs.

According to the federation, protection is patchy and poorly enforced, while wolf populations are increasingly threatened by hunting and the destruction of their habitats. Healthy but declining groups still exist in parts of Eastern Europe, Russia and Siberia. But most groups elsewhere in Europe are small and scattered - Italy, for example, has fewer than a hundred animals.

Josh Ginsberg, a researcher at the Institute of Zoology at London Zoo, points out that in addition to its traditional enemy, man, the wolf is now under threat from domestic dogs, which have been able to exploit the reduced size of the wolf population to mate successfully with females.

Researchers have recently discovered that supposedly purebred European wolf populations Canis lupus lupus, a subspecies of the gray wolf Canis lupus, are in fact mainly hybrids between wolves and dogs.

In order to tackle the problem, researchers at London Zoo and elsewhere are seeking to establish new captive populations of the European wolf. According to Douglas Richardson, assistant curator of mammals at London Zoo, this entails identifying purebred individuals using genetic fingerprinting and other techniques, and then establishing stable founder populations.

Most wolves now kept in British zoos are American hybrids. Richardson says that the first aim is to replace these with European wolves, adding that captive breeding pro-

\section{Stars in the eyes}

Washington. Although the world's spacefaring nations are hard pressed to launch even a modest-sized space station into Earth orbit, there's no harm in thinking grander thoughts. So about a hundred scientists, engineers and visionaries will gather in New York on 29 August to discuss the topic: 'Practical Robotic Interstellar Flight: Are We Ready?'

Under consideration will be where to go (possible planets around other stars, the Oort cloud), and how to get there (everything from fusion rockets to magnetic sails). The four-day conference is sponsored by the Planetary Society, a space advocacy group, with the British Interplanetary Society and several other organizations. grammes could be used either to top up existing populations or to reintroduce wolves into areas from which they have disappeared.

The British organization Wolfwatch is working with London Zoo on the possibility of reintroducing European wolves into Scotland: with more than 300,000 red deer there is more than enough food as well as space to support a significant wolf population.

IMAGE
UNAVAILABLE
FOR COPYRIGHT
REASONS

A dying breed? Efforts are needed to preserve the European wolf's genetic identity.

But Ginsberg admits that such a move is "politically unlikely". Hunters and farmers are likely to object, he says, while the public still regard wolves as dangerous, and the threat from dogs remains high. "Little Red Riding Hood has a lot to answer for," says Richardson.
But while zoologists and public associations are both backing wolf conservation, cooperation is often hampered by mutual distrust. Many of the groups making up the new federation say they oppose keeping wolves captive in zoos, and refuse to accept that zoos have a role to play in conservation.

For their part, zoologists often accuse amateur conservation groups of failing to take scientific advice into account, and of squandering resources on highly publicized but ineffective conservation schemes.

Richardson points out, for example, that the genetic make-up of founder populations needs to be monitored carefully, starting with captive groups. He also claims that amateur groups often fail to ensure that the reasons for the extinction of a species have been removed before attempting to reintroduce it. "They have to come to us if they want expertise," he says.

One event helping the European wolf to make a comeback is the removal of the fences and landmines in Eastern and Central Europe following the end of the Cold War. As a result, wolves have begun to spread from Poland into Germany, for example, says Richardson. The large-scale attempts to eradicate rabies from the mainland of Europe using a genetically engineered vaccine should also assist in conservation schemes.

Declan Butler

\section{Italy promises appointment reforms}

Munich. Stefano Podestà, Italy's minister for research and universities, has taken up a proposal originally made by Umberto Eco, professor of semiotics at the University of Bologna and author of The Name of the Rose, for reforming the country's controversial system of academic appointments.

The proposed system would involve drawing up a list from which universities could select individuals to fill vacant jobs. Podestà hopes that this and other suggestions will both increase the efficiency of the appointments system and reduce alleged malpractice.

At present, all academic posts in Italy are filled by national competitions (concorsi), which are supposed to take place every five years. National committees, one for each subject, select successful applicants who are then allocated to a university, not necessarily of their choice.

Italian scientists complain that the real selection of candidates results from behindthe-scenes dealings that are not always based solely on scientific merit, but can include deals between powerful faculty heads.

Addressing the final cabinet meeting before the summer recess, Podestà proposed that committees should select more candidates than there are places, creating a national list from which universities would choose candidates when a vacancy arises, instead of having to wait for the next concorso.

Podestà said that he wants to simplify the procedure for electing the selection committees, and to give his ministry the right to appoint foreign academics to these committees "as necessary". He also outlined proposals to abolish the post of associate professor, leaving only two academic ranks: junior researchers (who at present do no teaching) and full professors.

While some have welcomed the change, Carlo Bulletti, secretary of the Italian Federation of University Researchers, which has long campaigned for a change in the academic promotion law, says it is too early to judge whether the proposals really offer an improvement on the current system.

Particular concern has been expressed that if the position of associate professor is eliminated, Italy would be out of line with most other countries. Podestà will draw up a more detailed parliamentary discussion paper in September.

Alison Abbott 